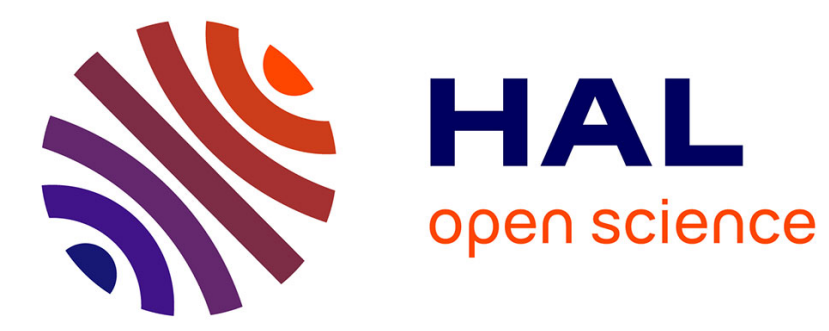

\title{
Becoming-with in Participatory Design
}

\author{
Sisse Finken, Christina Mörtberg, Pirjo Elovaara
}

\section{To cite this version:}

Sisse Finken, Christina Mörtberg, Pirjo Elovaara. Becoming-with in Participatory Design. 13th IFIP International Conference on Human Choice and Computers (HCC13), Sep 2018, Poznan, Poland. pp.258-268, 10.1007/978-3-319-99605-9_19 . hal-02001932

\section{HAL Id: hal-02001932 \\ https://hal.inria.fr/hal-02001932}

Submitted on 31 Jan 2019

HAL is a multi-disciplinary open access archive for the deposit and dissemination of scientific research documents, whether they are published or not. The documents may come from teaching and research institutions in France or abroad, or from public or private research centers.
L'archive ouverte pluridisciplinaire HAL, est destinée au dépôt et à la diffusion de documents scientifiques de niveau recherche, publiés ou non, émanant des établissements d'enseignement et de recherche français ou étrangers, des laboratoires publics ou privés. 


\title{
Becoming-with in Participatory Design
}

\author{
Sisse Finken ${ }^{1}$, Christina Mörtberg ${ }^{2[0000-0003-4160-4348]}$ and Pirjo Elovaara ${ }^{3[0000-0003-1760-6028]}$ \\ ${ }^{1}$ TiP Group, Dept. of Business IT, IT University of Copenhagen, Denmark \\ ${ }^{2}$ Dept. of Informatics, Linnaeus University, Växjö, Sweden \\ ${ }^{3}$ Dept. of Technology and Aesthetics, Blekinge Institute of Technology, Sweden \\ sisfeitu.dk \\ christina.mortbergelnu.se \\ pirjo.elovaara@bth.se
}

\begin{abstract}
We draw on feminist technoscience to analyze actions and activities performed between participants in a Participatory Design workshop that unfolds in a realm of e-government. Stepping into this empirical site we want to show how participants (invited persons, researchers, methods, artifacts, gender stereotypes) become with each other. With such take on research endeavors we feed into current discussion in feminist research by illustrating how theory and practice intertwine and create realities.
\end{abstract}

Keywords: Feminist Technoscience, Participatory Design, Ontology.

\section{Introduction}

"Staying with the trouble requires making oddkin; that is, we require each other in unexpected collaborations and combinations, in hot compost piles. We become-with each other or not at all. That kind of material semiotics is always situated, someplace and noplace, entangled and worldly." [1] ${ }^{1}$.

The opening quote is from Haraway's book [1] in which she seeks to: "cut the bonds of the Anthroposcene and Capitalocene" ${ }^{2}$ in that they carry with them logics of "techno-apocalypses" and "game over attitudes" . Such logics, Haraway argues, prevents us from staying with the troubles, which "is both more serious and more lively." the Chthulucene, which includes the "dynamic ongoing sym-chthonic forces and powers of which people are part, within which ongoingness is at stake." [2] $]^{5}$.

In drawing on Feminist theorizing - especially with concerns to 'become-with', 'situated', and 'ongoingness' as put forward in the above - we enter a reading of a Participatory Design (PD) workshop [3] and show how the inclusion of subjects and

\footnotetext{
${ }^{1}$ p. 4

2 p. $4-5$

${ }^{3}$ p. 3

${ }^{4}$ p. 4

${ }^{5}$ p. 160
} 
objects can fruitfully be read as material semiotic practices ${ }^{6}$ in which participants (invited persons, researchers, methods, artifacts, gender stereotypes) become-with each other and how they, rather than sitting still, are constituted in encounters. Thus, with the re-visit to the PD workshop our focus is on how entities are becoming with in boundary-making practices that unfold at the workshop. In line with this, [6] remind us that design is always situated. Being situated is also what [7] pleads for as a fundamental part of PD. They state: "[In fact, as we shall see,] the origination of participatory design as a design approach is not primarily designers engaging in use, but people (as collectives) engaging designers in their practice"7.

In this paper, we find inspiration in feminist technoscience strands in general and especially in Agential realism when engaging in a reading of the workshop, which we situate as an ongoing ontology [5]. That is to say that we acknowledge that boundaries between 'nature and culture', 'social and material', 'human and nonhuman' are not always obvious. Thus, with agential realism we are provided a possibility to understand how meaning and matter are constituted in material-discursive material semiotic practices, or, as something that emerges from "intra-actions" [5].

The paper is structured in the following way: first we coin our aim with reference to feminist technoscience and agential realism. We then move on to a short delineation of PD, especially focusing on previous work concerning feminism and PD. Next, we enter the empirical case, which is analyzed and discussed from a position of agential realism with explicit focus on bringing in ongoing ontology to participative endeavors. Lastly, we conclude the paper emphasizing how participants (methods, gender stereotypes, researchers, paper, pen, cars, civil servants, etc.) are becoming, and, thusly, that paying attention to the performance between (them) is important.

\section{Theoretical orientation}

When entering the workshop below, we are concerned about the actions and activities that take place between the involved participants and their making of each other in ongoing and evolving endeavors. But first, we introduce more carefully the theoretical concepts used.

'Intra-action' [5], is one central concept in agential realism, which illustrates that subjects and objects are not separate, but rather entangled. Højgaard et al. [8] say it the following way: "Everything is always engaging something else, in specific ways designated by concepts: intra-activity, i.e. matter and meaning, object and subject, nature and culture are mutually articulated and mutually entangled"8. Another central concept is that of 'apparatuses' [5]. In bringing in apparatuses we do not mean to highlight the ensemble of human and nonhumans, rather, we find it fruitful to empha-

\footnotetext{
${ }^{6}$ Haraway [4] uses material semiotic practices to grapple with entanglements of subjects and objects and Barad [5] uses material material-discursive. We treat these concepts as synonyms.

${ }^{7}$ p. 162

${ }^{8}$ p. 68
} 
size that: "apparatuses are specific material reconfiguration of the world" $[5]$. This means that apparatuses structure how we see, yet, at the same time they are not outside other orders (such as culture) that constitute what we see. This again means that apparatuses are part in the ongoing becoming of reality, of meaning and matter [9-10].

Apparatuses also enact cuts that: "produce "objects" of particular knowledge practices..." $[5]^{10}$ and "boundaries, properties, and meanings" 11 . It is the cuts that separate what will be called objects and subjects ${ }^{12}$. The objects and subjects do not pre-exist but their meanings emerge through agential cuts. The cuts are thereby not drawn once for all; but breaks ongoing activities due to the specific context where the intraactions take place, e.g. in a design process. The very design process is the enactment of agential cuts in which subjects, objects, properties, and boundaries unfold. The cuts are enacted in ongoing activities in a design process, but they also raise ethical issues, as any cut, even an agential cut, can hurt. While interaction builds on a principle of separation, intra-action represents two ontologically inseparable entities. The intraactions continue until a break is enacted. We make use of the concept agential cut in our reading of a PD workshop to understand each iteration in design as the enactment of a cut - a break in ongoing activities; a becoming-with each other.

In this article we bring in Barad's orientation to apparatuses by way of relating it to research methods. Such methods, which we bring along to the field and/or to the desk when engaging in research efforts - be it anthropological work or PD endeavors have a bearing on our orientations in the world and what comes to matter in ongoing 'intra-actions' (e.g. [5], [11, 12]).

In line with this, we could say that research and design methods are part of the worlds becoming. Photography, for example, is something more than a way to document, or representing, reality; it is an apparatus (beyond the camera or video recorder) that enacts and re-configures different realities through in- and exclusions. Such inand exclusions could be focused/blurred areas on a photo, the very cut of the world (what is outside the frame of the photo?, who is behind the camera?), and/or the very framing of a scenery and/or creation of e.g. otherness, eternal sunshine, good looks in line with a given time's beauty codex [13]. Similarly, the design method used at the present workshop, "mapping practices" [3] becomes one way of meeting, sensing, and looking into [14] whether the endeavor is audio recorded, videoed, or jotted down on paper. This also goes for the different material brought along to the workshop (such as pens, paper, images, glue, etc.), and it goes for the questions we ask, the interviews we perform, and the observations we make. They are ways of conduct that have ontological consequences. Accordingly, PD methods are modes of doing that draw out different boundaries, and such boundary-making in- and excludes. This again influences what comes about in 'intra-action' [5]. Barad reminds us that it is necessary to draw boundaries to create meaning, and that these boundaries have "materialconsequences" $[15]^{13}$. Thus, boundary-making is not taken for granted since it is not

\footnotetext{
${ }^{9}$ p. 142

${ }^{10}$ p. 147

${ }^{11}$ p. 340

12 p. 333

${ }^{13}$ p. 187
} 
innocent; it has "ontological implications" [9] ${ }^{14}$. Similarly, the methods brought along to PD sites have ontological implications. And the (so called) outcome from these PD sessions - be it service designs, reports, information technologies, or scientific texts (like this one) - draws out different boundaries and should, accordingly, be seen as ongoing re-configurations of the world, rather than representations of encountered practices. PD efforts and the involved participants (e.g. methods, materials, discourses, identities), per se, are not definite static entities that interact - they are becomings of this world.

With this, we wish to make a feminist technoscientific intervention that concerns a caring for the very actions and activities that are performed between participants.

\section{$3 \quad$ Participatory Design}

PD centers its ideology and practices on involvement of participants in design endeavors. The early formation of PD took its offspring in the 1970:ies in cooperation with Scandinavian labor unions as an effort to empower workers through development of workplace information technology [16]. 'Democracy', 'critical', and 'participant driven' are terms to be used when describing PD. Further, PD can be described as a design approach that builds on visions concerned with involving multiple voices in design processes [17]. PD centers on participative methods and democratic practices, it inspires mutual learning, and it advocates for locating and situating practices and actions in the contexts of the participants involved [17]. Such guiding principles concern accountability and its importance for PD and its praxis. Within PD various methods and techniques - e.g. mock-ups, prototyping, workshops, scenarios, interviews are used to establish grounds for communication and mutual learning in the design processes.

For the purpose of the present paper, we leave aside the more general descriptions of PD and engage work that has been concerned with bringing in gender or feminist perspectives into PD.

Markussen [18] discusses experience and how both users and designers are implicated in the design process. The image of an invisible designer is contested by asserting his/hers presence as co-creator and accountable in the creation of realities or mattering in PD processes (see also [19]).

Another example is found in Sefyrin [20] who discusses design as sociomaterial practices in which participation, gender, power, and knowledge are intertwined. Sefyrin builds her discussion on an ethnographic study of an eGovernment project performed in a Swedish government agency. To expand design to be sociomaterial includes both human and nonhuman actors. Methods, visions, organizational boundaries, innovation practices, gendered practices are examples of the latter. The administrative officers - all women - were central actors in the entire project depending on their knowledge and experiences of the work practices. Sefyrin illustrates how sociomaterial encounters (e.g. the business process analysis method, gendered division of

${ }^{14}$ p. 73 
labor, organizational boundaries, and changed project objective), intersect with human actors that reconfigured the administrative officers from being core knowers to becoming marginalized knowers with restricted agency. Sefyrin concludes her work stating that participation: "comes into being in situated practices. With this view participation is fluid and shifting; the result of the ongoing intra-actions of gender, power, knowledge, and various sociomaterial practices"15.

Hence, feminist scholars have focused on PD, both as a design practice and from more theoretical angles. Bath [21] can be positioned in the latter when she scrutinizes a number of design approaches with the intention to develop an approach she calls the degendering of technology. Bath argues, that PD can contest the inscription of gender in design, but she emphasizes that the approach is also open to certain objections. One such is that PD implies a taken-for-granted-ness in terms of the possibility of inscribing emancipatory ideas into technology. Another tendency of feminist PD researchers is to re-essentialize gender when they pay attention to skills and competences aiming at making also women's work visible [21]. Although feminist researchers have explored PD as a gendered process, Bath asserts that it is necessary to explore PD further. We intend to follow Bath's remark.

$\mathrm{PD}$ is a value-centered approach that is both political and ethical motivated. An exploration of whose values that intervene in a PD process has resulted in a reconfiguration of the designer from being invisible and everywhere to becoming positioned somewhere and accountable [18], [22, 23]. Accountability is a key concept in PD. It is viewed by [24] as an expression of PD's ethical stand, they write: "an accountability of design to the worlds it creates and the lives of those who inhabit them." ${ }^{\prime \prime}$.

However, it is not only values that emerge in PD projects; rather, all entities included in the design process are co-constituted. In borrowing from Barad's work [5], we understand each intra-action in PD projects as the enactment of a cut, in which subjects and objects emerge. Thus, to understand PD as becoming means that it depends on what is included and what is excluded. The design process that takes place in the present workshop is the enactment of cuts in which entities get their meanings. With this, it is our desire to discuss PD-based design practices as an ongoing becoming with each other [1].

\section{$4 \quad$ Realities emerge}

The workshop was held in 2005 within the research project 'From government to egovernment: gender, skills, technology and learning'. The project was conducted as a joint research and design activity between two of the authors and a number of female public-sector employees from five south-Swedish municipalities. The intention with the project was to bring everyday practices, which are absent in governmental policies, into the design of digital services. Within the project we organized several workshops based on the design ideology of participation both of the design researcher and practitioners [3]. Our concern was to work with design methods, which were easy to

\footnotetext{
${ }^{15}$ p. 118

${ }^{16}$ p. 5
} 
transport and easy to use, and not demanding preparations or too much investment in time.

In entering intra-actions in the workshop, we are reminded of Barad's [5] words that boundary-making is necessary, it is not innocent, and it in- and excludes. That is, e.g., happiness came into being in the meeting between the director of the cityplanning department (Kerstin) and us (two researchers) when she welcomed us. Kerstin introduced two other civil servants (the urban planners Maria and Nina) and a conference room to be used for the workshop.

At the workshop, the encounter between images, hands, glue and white sheet a first way to present themselves (Kerstin, Maria and Nina) emerged. Within this, the researchers and their method also came into being. This first encounter initiated a conversation with comments such as "she is like I" or "this woman reminds me of the leading politician in this municipality". The intra-activities continued in the encounter between Kerstin, Maria, Nina, the two researchers, pictures of furniture cut out from magazines, and the technical equipment. New encounters emerged when images were glued on to a big white sheet in an effort to create a narrative of the civil servants' work and workplace. Simultaneously, with these mapping activities, the civil servants and researchers talked and discussed. In the design process - at the workshop - the enactments of cuts got their meaning from the included entities. Cuts, e.g., were performed when the civil servants explained why and what they pasted on to the sheets. That is, the entanglements were reconfigured and the boundaries between the entities became obvious. At other times the researchers' questions, clarifications, or other entities created cuts.

The enrolled audio recorder also participated and recorded the experiences at the workshop. In this way, we could say, a reality of "practice" does not exist as a fixed one; rather it comes into being between our actions, materials, the methods, and the discourses we include [25]. When listening to the documentation afterwards, the recorder prompted us to more carefully pay attention to a specific situation in which a picture of a car was requested. That is, at a certain point during the workshop Maria suddenly expressed a need for a car. This request interrupted the ongoing activities of gluing and conversing. I.e., a cut is enacted when Maria uttered: "I need a car" and "I can't find any". In response to her request, she was suggested to "draw a car". This little request and the responding suggestion we hardly paid attention to during the event of workshop, but it became apparent later on via the audio recorder. I.e., during the mapping, Maria articulated a need for including other materials than the ones brought along to the workshop site by the researchers. The cut reconfigured the involved participants and made obvious that in previous intra-actions (in the event of preparation for the workshop) neither cars nor mobility had been included. This cut reconfigured the researchers' knowing about the civil servant as an indoor urban planner; she was also working outdoor and being mobile. Within this, Maria's visits to and travels between her office and e.g. construction projects or construction enterprises unfolded by this very cut. We read this as a "becoming with" that was made apparent by the audio recorder.

In addition, Maria's need highlighted how boundaries drawn in previous enactments - not including a car or mobility - came to have ontological implications in 
later iterative intra-actions [9]. Barad [5] writes: "[indeed], intra-actions iteratively reconfigures what is possible at a given moment and what is impossible - possibilities do not sit still, ${ }^{17}$. In a new intra-action it is possible to include what was excluded in a previous one. At the workshop, the sketched car came into being in an encounter between the participants, a hand, a pen, and a paper. This reconfigured the civil servant - she became a mobile subject (urban planner) between their devices or materiality in form of the sheet, images, pens, lines, colleagues and their relationships.

Further, this situation can be read as an example of another kind of configuration in that the civil servants are reconfigured from participants in and users of material (brought along to the workshop) to designers and facilitators of such. And, in turn, we can read this as an example in which the two researchers are constituted as researchers in the very encounter between their documented research material, the participative workshop, Barad's theories, enacted cuts, new materials, and knowing.

Another encounter documented by the recorder was the entanglements of governing principles. We should mention here that a municipality is governed by various policies and principles decided by politicians, which are then translated and implemented by the civil servants. In this example from the workshop Maria and Nina included two dominating governance principles: "What does the plan tell us?" and "Is this proposal aesthetically acceptable?". The boundaries were drawn differently with respect to how they previously had been drawn at the workshop. Both the city-plans and aesthetic issues co-emerged. Problems or different views on how to construct the roof of a new planned building - cheep, simple, functional opposed to aesthetics, also came into existence when relationships were entangled. In this way, we could say, agency not only relates to humans; rather, it is something that is performed in actions. In an interview, Barad explains that agency is neither limited to humans nor to something one possesses; Rather it "is an enactment, a matter of possibilities for reconfiguring entanglements" $[26]^{18}$. The entanglements were changed including new possibilities that reconfigured the participants, the maps or the world that came into being through the actions and doings with the inclusion of external and internal relationships. Hence, this illustrates how agency is situated and continues in research practices - in its "ongoiness" [1]

At the workshop, narratives unfolded in intra-actions between the sheet, people, and technologies. The stories also included accounts about how Maria and Nina are greeted when in contact with construction enterprises, agencies, politicians, and citizens. Maria and Nina said: "It is the "old boys" and "we are the young blondes". They told about how their looks, age and gender are commented on, how they reflect upon these meetings with anger, and, at the same time, determined professionalism. Nina and Maria touched the male dominated Swedish construction sector in their extension of their practices and doings. Age, gender, and professionalism are constituted or becoming with their touches. Thus, the urban planners "play in the intertwined practices of knowing and becoming" $[12]^{19}$ when they become "the young

\footnotetext{
${ }^{17}$ p. 234

${ }^{18}$ p. 54

${ }^{19}$ p. 812
} 
blondes" vis-a-vis construction enterprises and other external partners who become "the old boys". Although asymmetrical power relations (old boys - blondes) are constituted in this entanglement it became reconfigured when one of the researchers said: "You possess power". Maria and Nina responded: "yes, we are able to say no" since the permission to build is approved by the urban planners.

Gradually the urban planners and the city-planning department's day-to-day activities unfolded in a co-emergence with a range of entities. The material semiotic reality was intertwined in the workshop - in the mappings or civil servants "grapples with the ordinary" $[27]^{20}$. Thus, realities were created between actions and doings. This became obvious, for example, in the start of the workshop when various images were discussed and explained before the civil servants chose and pasted one image of themselves on to the sheet.

Here we leave the city-planning department, Kerstin, Maria, Nina, and everybody else present at the workshop and continue with a discussion of the workshop in terms of bringing in ongoing ontology to participative endeavors.

\section{$5 \quad$ Coming into being}

At the workshop, participants 'become-with' in 'ongoingness' [1]. That is, the different images, pens, scissors, post-it-notes, paper sheet, tables, whiteboard, words, methods, tape recorder, cuts, blonde planners, expert planners, old boys, local politicians, citizens, business contacts, researchers are "reconfigured and reconfiguring" $[5]^{21}$ in "ongoing process[es] of (re-)production over time and across sites." $[28]^{22}$. This we encountered at the workshop where some participants were present from the very beginning, others were constituted through new entanglements, and yet others again through listening to the audio recordings.

Thus, what we have aimed at, with this reading of the workshop, is to make a feminist technoscientific intervention that shows how meaning and matter come into being between, rather than in-between clearly defined empirical entities. Specifically, Barad explains in an interview that she is concerned with actions between constituents: "[...] intra-action conceptualizes that it is the action between (and not inbetween) that matters." $[26]^{23}$. In our reading, thus, meaning and matter emerge out of entanglements through which new possibilities become. Bringing such understanding along to participative efforts reflects what goes on in these research sites - they become, with other words, "critical sites" $[28]^{24}$.Such understanding is important when entering processes of research efforts on which realizations of future technologies/services, and/or scholarly accounts are based.

At the workshop a range of participants became-with each other in the mapping practice. In this way, neither the civil servants nor the researchers were "outside ob-

\footnotetext{
${ }^{20}$ p. 3

${ }^{21}$ p. 235

${ }^{22}$ p. 278

${ }^{23}$ p. 14

${ }^{24}$ p. 267
} 
servers of the world" $[5]^{25}$; but, we could say, they came into existence in the intraactions that took place at the workshop. An example of such is the situation with the car that was included and which came to reconfigure knowing and being of both researchers and civil servants. In this way, entanglements of meaning and matter matters in the processes that took place. Various realities were created depending on what was included and excluded in the practices of the different participants present. Further, the inclusion of e.g. a car illustrates how new possibilities emerge when subjects and objects meet.

At the workshop, other participants, than those of humans, paper, scissors, images, gender stereotypes, and identities were present. These others are by another name called 'methods' (or 'apparatuses'). They are created and included with the purpose of achieving something like participative practices; but, at the same time, these methods are not outside; they are part in constituting our very performance. Along these lines, design methods are something more that tools produced and used by humans; they have a bearing on our "becoming with", and what comes to matter. In this way, design methods (workshops, mapping practices) and other research methods (interviews, observations) are also modes of doing, which have ontological implications [5], [11, 12], [25].

With this we mean to highlight that they iteratively configures and reconfigures our world and give it particular material form [5].

\section{Conclusions}

In our call for a feminist technoscientific intervention we sat out on a route delineating issues of concern within Participative Design. We then entered a workshop where a range of participants (methods, gender stereotypes, researchers, cars, civil servants, etc.) met and came into being in ongoing entanglements. In the analysis we considered actions between participants; i.e. that which intra-acts in practices. This paper, thus, is concerned with reflecting the becoming-with in participative research endeavors. Along these lines, we want to emphasize PD's central concern for accountability, which entails strong ethical attentiveness towards design practices as situated and locally bound, and towards design outcomes, which are considered with respect to the consequences they may have for those practices.

With our concern for encounters and emergencies that come about in activities, we have wanted to show the fruitfulness of being concerned about 'become-with', the 'situated', and 'ongoingness' [1] in everyday and research practices. With this we gesture to Science and Technology Studies and Feminist Technoscience, e.g. [5], [29, 30, 31], and ask: who participates in the research processes; what do these participants do; with what effects, for whom? And how are such participants accounted for in design practices? What kind of ontological implications do boundary-making practices have with their in- and exclusions?

${ }^{25}$ p. 182 
In an effort of keeping the accountable heart of PD alive, we ask for new questions that are related to ontological understandings precisely because they have consequences for design practices and outcomes. By way of inviting feminist technoscience into PD we hope to bring about fresh strands that can contribute to PD-based design practices as situated and becoming-with in its ongoingness.

\section{Acknowledgement}

This paper is 'becoming-with'. It would not have been the same without the participating civil servants, research methods, materials, discourses, comments from previous reviewers, Helena Karasti, two HCC13 reviewers, theories, email, internet, etc. We thank you all.

\section{References}

1. Haraway, D. J.: Staying with the Troubles. Making Kin in the Chtulucene. Duke University Press (2016).

2. Haraway, D. J.: Anthropocene, Capitalocene, Plantationocene, Chthulucene: Making Kin. Environmental Humanities, vol. 6, pp.159-165, (2015).

3. Elovaara, P. \& Mörtberg, C.: Cartographic Mappings - Participative Methods. In Bødker, K., Brattetei, T., Loi, D. \& Robertson, T. (eds.) Proc. of PDC 2010, pp. 171-174. Sydney, Australia (2010).

4. Haraway, D. J.: Modest_witness@second_millenium. Female man ${ }^{C}$ meets_oncomouse ${ }^{\mathrm{TM}}$ : Feminism and technoscience. Routledge, New York and London: Routledge (1997).

5. Barad, K.: Meeting the Universe Halfway. Quantum physics and the entanglement of matter and meaning. Duke University Press (2007).

6. Suchman, L., Trigg, R. \& Blomberg, J. (2002): Working artefacts: ethnometods of the prototype. British Journal of Sociology 53(2), 163-179 (2002).

7. A.Telier: Design Things. By Binder, T., De Michelis, G., Ehn, P., Jacucci, G., Linde, P. \& Wagner, I. MIT Press (2011).

8. Højgaard, L. Juelskær, M. \& Søndergaard, D.M.: The "WHAT OF" and the "WHAT IF" of Agential Realism - the Search of the Gendering Subject. Kvinder, Køn og Forskning, NR 1-2, 67-68 (2012).

9. Hekman, S.: The Material of Knowledge: Feminist Disclosures. Indiana University Press (2010).

10. Irni, S.: Indeterminate Matter. NORA - Nordic Journal of Feminist and Gender Research, $18: 1,52-56(2010)$.

11. Foucault, M.: On the Genealogy of Ethics: An Overview of Work in Progress. In Dreyfus, H. L. \& Rabinow, P. (eds.) Michel Foucault: Beyond Structuralism and Hermeneutics, pp. 229-252. The University of Chicago Press (1983).

12. Barad, K.: Post-humanist performativity: Toward an Understanding of How Matter Comes to Matter. Signs: Journal of Women in Culture and Society 28 (3), pp. 801-31(2003).

13. Crang, M. \& Cook, I.: Doing Ethnographies. Sage Publications (2007).

14. Barad. K.: On Touching-The Inhuman That Therefore I am. differences: A Journal of Feminist Cultural Studies 25(3), pp. 206-223 (2012). 
15. Barad, K: Meeting the universe halfway: realism and social constructivism without contradictions. In L. H. Nelson \& J. Nelson (Eds.) Feminism, Science, and the Philosophy of Science, pp. 161-194. Dordrecht: Kluwer Academic (1996).

16. Finken, S.: Discursive Conditions of Knowledge Production within Cooperative Design. SJIS, Vol. 15, pp. 57-72 (2003).

17. Kensing, F. \& Greenbaum, J.: Heritage Having a Say. In Simonsen, J. \& Robertson, T. (Eds.) Routlegde International Handbook of Participatory Design, pp. 21-36. New York: Routledge (2012).

18. Markussen, R.: Politics of Intervention in Design: Feminist Reflections on the Scandinavian Tradition, AI \& Soc. 10(2), 127-141 (1996).

19. Vehviläinen. M.: Gender, expertise and information technology. University of Tampere, Department of Computer Science, Tampere (1997).

20. Sefyrin, J.: Entanglements of Participation, Gender, Power and Knowledge in IT Design. In Bødker, K., Bratteteig, T., Loi, D, \& Robinson, T, (Eds.) Proc. of PDC, pp. 111-120. Sydney, Australia: ACM Press (2010).

21. Bath, C.: Searching for Methodology: Feminist Technology Design in Computer Science. Paper presented at 5th European Symposium on Gender \& ICT. Digital Cultures:Participation - Empowerment - Diversity, March 5 - 7, University of Bremen (2009).

22. Suchman, L. Located accountability in technology production. SJIS 14(2), 91-105 (2002).

23. van Der Velden, M. \& Mörtberg, C.: Participatory Design and Design for Values. In Handbook of Ethics, Values, and Technological Design: Sources, Theory, Values and Application Domains, pp. 41-66. Springer (2015).

24. Robertson, T. \& Simonsen, J.: Participatory design. An Introduction. In Simonsen, J. \& Robertson, T. (Eds.) Routledge International Handbook of Participatory Design, pp. 1-17. New York: Routledge (2012).

25. Hekman, S.: Constructing the Ballast: An Ontology for Feminism. In Alaimo, S. \& Hekman, S. (eds.) Material feminism. Indiana University Press (2008).

26. Dolphijn, R. \& van der Tuin, I.: New Materialism: Interviews \& Cartographies. Open Humanities Press (2012).

27. Haraway, D. J.: When species meet. Minneapolis: University of Minnesota Press (2008).

28. Suchman, L.: Human-Machine Reconfigurations. Plans and Situated Actions. Cambridge University Press (2007).

29. Foucault, M.: The History of sexuality. Volume 1: An Introduction. Vintage Books (1990).

30. Latour, B.: On recalling ANT. In Law, J. \& Hassard, J. (eds.) Actor Network Theory and after, pp. 15-25. Blackwell Publishers (1999).

31. Mol, A.: The Logic of Care: Health and the problem of patient choice. Routledge (2008). 